Title:

Elemental and molecular analysis of metal containing biomolecules using laser induced breakdown spectroscopy and sonic spray ionization mass spectrometry: A step towards full integration and simultaneous analysis

Authors:

Konstantinos Marmatakis, Spiros A. Pergantis, Demetrios Anglos

Manuscript

The original publication may be found at:

Journal: Spectrochimica Acta Part B 126, 103-109 (2016)

DOI: http://dx.doi.org/10.1016/j.sab.2016.10.020 


\title{
Elemental and Molecular Analysis of Metal Containing Biomolecules Using Laser Induced Breakdown Spectroscopy and Sonic Spray Ionization Mass Spectrometry: A Step Towards Full Integration and Simultaneous Analysis
}

\author{
Konstantinos Marmatakis ${ }^{1,2}$, Spiros A. Pergantis ${ }^{1}$, Demetrios Anglos ${ }^{1,2}$ \\ ${ }^{1}$ Department of Chemistry, University of Crete, GR 71003 Heraklion, Greece \\ ${ }^{2}$ Institute of Electronic Structure and Laser, Foundation for Research and Technology \\ - Hellas, P.O. Box 1385, GR 71110 Heraklion, Greece
}

\begin{abstract}
A novel methodology is proposed that combines sonic spray ionization (SSI) mass spectrometry (MS) with laser induced breakdown spectroscopy (LIBS) for analyzing metal-containing biomolecules and complexes. Focusing pulses from a nanosecond laser (Nd:YAG, $\lambda=1064 \mathrm{~nm}$ ) in the microdroplet ensemble produced by a pneumatic nebulizer yielded LIBS spectra that enabled highly sensitive detection of several metal ions in aqueous and aqueous methanolic solutions. Based on the calibration curve method, LOD values at the $\mathrm{ng} / \mathrm{mL}$ level were achieved for $\mathrm{Ca}(15 \mathrm{ng} / \mathrm{mL}), \mathrm{Ba}$ (27 ng/mL), $\mathrm{Cu}(67 \mathrm{ng} / \mathrm{mL})$ and $\mathrm{Fe}(650 \mathrm{ng} / \mathrm{mL})$ with accuracy greater than $90 \%$. LIBS measurements were performed for the first time on aerosols of solutions of known biomolecules such as superoxide dismutase and alpha-lactalbumin, which led to the reliable determination of the concentration of $\mathrm{Cu}$ and $\mathrm{Ca}$, respectively, both in the range of a few $\mu \mathrm{g} / \mathrm{mL}$. In parallel, the relative molecular mass of the metalloproteins was determined by separate SSI-MS measurements performed using an identical pneumatic nebulizer based sample introduction system. This is a first step towards the ultimate aim of integrating the two analytical techniques by use of a single pneumatic nebulization system for simultaneous sample introduction for both LIBS and SSI-MS. Such a system is expected to greatly enhance our capabilities to simultaneously acquire molecular and atomic data.
\end{abstract}

Keywords: Laser-induced breakdown spectroscopy; Sonic Spray Ionization Mass Spectrometry, Aerosols, Metalloprotein 


\section{Introduction}

The necessity to further understand the biotransformation of metals and metalloids in biological systems has promoted elemental speciation analysis to become a vital bioanalytical procedure. This has been assisted by the tremendous progress made in the development of novel analytical methods, mainly based on advanced hyphenated techniques, incorporating a separation using gas chromatography (GC) or liquid chromatography (LC) coupled on-line with an element specific detector such as inductively coupled plasma mass spectrometry (ICPMS) and/or a molecular detector such as electrospray tandem mass spectrometry (ESMS/MS). [1-8]

As a result, significant capabilities for the speciation of $\mathrm{As}, \mathrm{Se}, \mathrm{Sb}$ and several other elements have been developed and applied, especially for the characterization of small biomolecules[9-13]. This has allowed for relatively high throughput, almost routine elemental speciation analysis for several elements in several different sample types. However, little progress has been achieved in the detection of metals present in larger biomolecules such as peptides or proteins, especially for high throughput, high coverage analyses. Metalloproteins, for example, constitute a large group of proteins that essentially avoid direct detection of their metal content during the most popular bottom-up MS-based proteomics analysis, in which proteins are digested, peptides are detected and proteins are identified from database searches. This approach only allows for the indirect identification of metalloproteins, since their metal content is not determined and is thus not verified. For direct metal determination a separate analysis is therefore required. However, once again it is difficult to associate the determined metal content to any specific protein, unless the protein has been isolated. Molecular MS of intact proteins (native mass spectrometry) can in some cases provide this vital information. However, even in such cases, limitations exist, most importantly concerning difficulties in detecting monoisotopic elements present in proteins, or metals in high molecular weight proteins or protein complexes, especially when the mass spectrometer does not provide sufficient resolving power. In addition, quantification of the metal present in the protein is extremely difficult.

Such limitations promote the need for a more integrated approach towards acquiring molecular and atomic data during the analysis of biological systems in order to detect the presence of metal and metalloid containing biomolecules, as well as to investigate interactions of metal species with biomolecules. The objective of this study is to explore the possibility to develop a combined molecular and atomic detection system suitable for analyzing metal-containing biomolecules and complexes. To achieve this we have investigated the use of sonic spray ionization (SSI) mass spectrometry (MS) in combination with laser induced breakdown spectroscopy (LIBS), thus exploring the possibility to fully integrate them.

Sonic Spray Ionization Mass Spectrometry was selected in this case for molecular detection, as opposed to the widely used electrospray source, because it offers many attractive features making it ideal for coupling with LIBS [14,15]. First 
of all there is no need to use a pump for sample injection (because of self-aspiration) or high voltage and heat for droplet and gas-phase ion formation. The production of positive and negative charged ions occurs simultaneously, the signal-to-noise ratio is high, molecular fragmentation is absent, formation of dimers is negligible and it provides high sensitivity.

Laser induced breakdown spectroscopy, on the other hand, is a very convenient technique for detecting and monitoring metallic ions. It offers several important advantages such as the capability to analyze samples in all three phases, solids, liquids or gases with minimal or zero sample preparation, it is non-destructive, and enables multi-element detection [16-18]. The relatively straightforward experimental setup for LIBS permits development of compact, versatile units that can be easily combined with other instrumentation or even operated as mobile instruments for in situ analysis of materials [19]. While most applications focus on the analysis of solid samples, several researchers have demonstrated the benefits of using LIBS for probing liquids, aerosols, particulates and gases [20,21]. The simplicity of operation and speed of data analysis makes LIBS an attractive choice for fast elemental analysis and an excellent one for combination with SSI-MS.

Probing of aerosols by LIBS has attracted the interest of researchers since the early 1980's and was mainly motivated by the need to improve LIBS performance in liquid sample analysis. Converting a liquid to aerosol has clear benefits arising from the generation of plasma in a gaseous rather than a bulk liquid environment. Plasma quenching processes are drastically reduced while contamination of optics due to splashing is totally eliminated. It is noted that Cremers [22] and co-workers in 1983 reported the analysis of $\mathrm{Be}, \mathrm{Na}, \mathrm{P}, \mathrm{As}$ and $\mathrm{Hg}$ containing aerosols in air with $\mathrm{LOD}$ values in the low $\mu \mathrm{g} / \mathrm{mL}$ range. Likewise, Omenetto [23] and co-workers studied $\mathrm{Na}$ containing sulfuric acid aerosols by LIBS and showed the potential of the technique for probing contaminants in industrial plants. Furthermore, Hahn and Buckley [2426] have made systematic investigations on the mechanisms associated with plasma formation in aerosols and in particular plasma-droplet (or particle) interactions with the aim of understanding the role of key experimental parameters in enhancing the analytical performance of LIBS in aerosol monitoring.

In the present study we have investigated the combined use of SSI-MS and LIBS, and discuss the benefits of the proposed analytical approach, reporting for the first time both molecular and atomic data from the analysis of metalloproteins in water-methanol solutions. At this stage LIBS and SSI-MS were applied separately. In both systems, the sample was analyzed in the form of aerosol that was generated by means of a pneumatic nebulization system, operated under nearly identical conditions, as regards sample flow rate, gas flow and solvent matrix. SSI-MS analysis provided the relative molecular mass of the protein whereas LIBS led to the determination of the protein metal content. It is noted that optimization of experimental parameters, relevant to LIBS analysis of the aerosol, permitted the accurate determination of metal ions at the sub- $\mu \mathrm{g} / \mathrm{mL}$ range. This work constitutes proof of principle for the 
possibility of establishing combined and simultaneous LIBS and SSI-MS analysis using a single sample introduction system.

\section{Experimental Section}

Aerosol LIBS: A standard LIBS experimental arrangement was employed that was properly modified in order to accommodate a pneumatic nebulizer as a sample source in the laser-sample interaction area (Fig. 1). In brief, pulses at $\lambda=1064 \mathrm{~nm}(\tau=8 \mathrm{~ns})$, from a Q-switched Nd:YAG laser (Series 5000, BMI, France), focused via a planoconvex lens $(\mathrm{f}=+50 \mathrm{~mm})$, lead to plasma formation within the volume of an aerosol spray, generated in ambient conditions by the pneumatic nebulizer (TR-30-C1, Meinhard®, Golden, CO, USA). Argon is used as a nebulization gas, at a pressure of $60 \mathrm{psi}$, producing a fine aerosol spray from an aqueous solution. The liquid microdroplets, typically formed by pneumatic nebulizers, have a relatively tight size distribution centered at approximately $10 \mu \mathrm{m}$ in diameter and expand in a conical geometry with a vertex angle of approximately 35 degrees [27]. In the present study the pneumatic nebulizer used was modified by inserting a $10-15 \mathrm{~cm}$ piece of fused silica capillary ( $100 \mu \mathrm{m}$ i.d. $\times 200 \mu \mathrm{m}$ o.d.) resulting in a free aspiration with a sample flow rate of $20 \mu \mathrm{L} / \mathrm{min}$. This is expected to result in microdroplet clouds with densities on the order of $10^{6}$ droplets $/ \mathrm{cm}^{3}$ and expansion velocities in the range of 30$80 \mathrm{~ms}^{-1}$, as already reported for conventional pneumatic nebulizers [27]. The laser beam intersects the aerosol at 90 degrees with respect to the axis of the spray cone. Both the laser beam propagation and the nebulizer axes lie in the horizontal plane. Precise adjustment of the nebulizer position with respect to the laser beam focus is achieved by means of a $x-y-z$ micrometer resolution translation stage. In the current measurements the tip of the nebulizer is positioned at a distance of $\mathrm{d}=2 \mathrm{~mm}$ from the laser beam axis, while the spray axis is shifted by a distance of $\mathrm{h}=2 \mathrm{~mm}$ in front of the laser beam focal point. The latter is critical in order to ensure optimum laser-spray interaction and avoid breakdown taking place outside the spray cone or at the edge of it. The exact location of the laser beam focal point is determined by observing plasma forming in air at near breakdown threshold conditions.

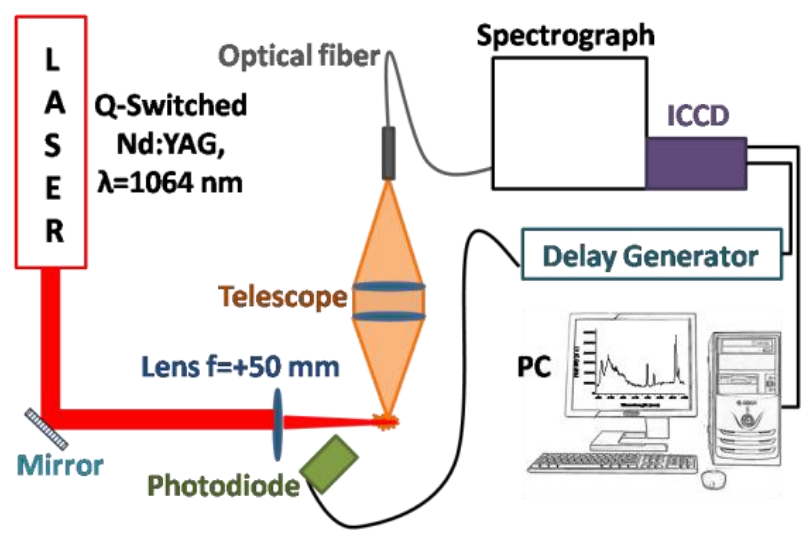




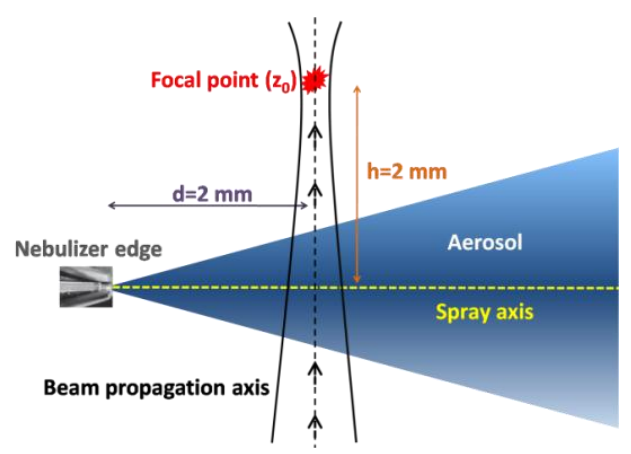

Figure 1. Schematic of the LIBS experimental setup (upper) and detail showing the position of the nebulizer and the aerosol spray expansion cone with respect to the focusing laser beam (lower).

Typical laser pulse energy values in this series of measurements have been in the range of 190-200 $\mathrm{mJ}$, corresponding to an energy density of approximately $6.5 \times 10^{3} \mathrm{~J} \mathrm{~cm}^{-2}$ at the focus or equivalent power density of $8.1 \times 10^{11} \mathrm{~W} \mathrm{~cm}^{-2}$. It is noted that, under these irradiation conditions, strong plasma emission is observed both in the presence of the aerosol and in air. The light emitted by the plasma plume is collected vertically by use of a telescope system consisting of two fused silica lenses $(f=+50$ $\mathrm{mm}$ ) and imaged at 1:1 magnification on one end of a quartz optical fiber (diameter: $600 \mu \mathrm{m}$ ) coupled, with its other end, to a Czerny-Turner imaging spectrograph (PTI, 01-002AD). The spectrograph is equipped with two holographic diffraction gratings, 300 grooves/mm and 1200 grooves $/ \mathrm{mm}$, covering a spectral range of $280 \mathrm{~nm}$ and 70 $\mathrm{nm}$ with a resolution of $0.4 \mathrm{~nm}$ and $0.1 \mathrm{~nm}$, respectively. An intensified CCD detector (ICCD, Andor iStar DH740-18F-03) attached to the spectrograph was employed for the time-resolved acquisition of the plasma spectral emission. The laser - detector synchronization was achieved via a digital delay generator (DG535, Stanford Research Systems) triggered by the output signal from a fast photodiode detecting the incoming laser pulses. The photodiode signal defined the "time zero" or start point of each measurement and the delay generator provided a trigger pulse at a variable time delay $\left(\tau_{\mathrm{D}}\right)$ with respect to the laser pulse activating the ICCD and determining the signal acquisition time interval or gate window, $\tau_{\mathrm{G}}$. The influence of the temporal acquisition parameters on the quality of the data (signal-to-noise and signal-tobackground ratio) was investigated and the optimal values used in this study were $\tau_{D}=$ $20 \mu \mathrm{s}$ and $\tau_{\mathrm{G}}=100 \mu \mathrm{s}$. All spectra reported herein correspond to the average of 5 sets of 200 single-laser shot spectra accumulation. The laser operates at a repetition rate of $5 \mathrm{~Hz}$.

Mass Spectrometry: The experimental setup employed for the SSI-MS measurements (Figure 2), consisted of a prototype SSI source (Elemental Scientific Inc., Omaha, USA) fitted with the same pneumatic nebulizer as the one used in the LIBS experiments, mounted onto an ion trap mass spectrometer (LCQ Advantage, Thermo Scientific). The nebulizer was modified as stated for the LIBS experiments, i.e. insertion of fused silica capillary, and operated using nitrogen gas at a pressure of 
60 psi corresponding to a gas velocity higher than 1 Mach. The use of this SSI source for molecular mass spectrometric characterization of metalloproteins, peptides and coordination compounds has been reported in previous studies. [28,29] The ion transfer capillary temperature was set to $300{ }^{\circ} \mathrm{C}$ and the acceleration potential, which directs the ions to the mass analyzers was set to $20 \mathrm{~V}$. The mass spectrometer covers a range from 100 to $2000 \mathrm{~m} / \mathrm{z}$ with a resolution of $1 \mathrm{~m} / \mathrm{z}$. Due to the relatively narrow mass detection range of the spectrometer, extensive protonation of the protein is necessary so as to reduce the $\mathrm{m} / \mathrm{z}$ ratio and for this reason, acetic acid was used as a proton source at a concentration of $2-5 \% \mathrm{v} / \mathrm{v}$. The ion trapping time was typically set to $400 \mathrm{~ms}$, and integration was conducted on 3 scan events.

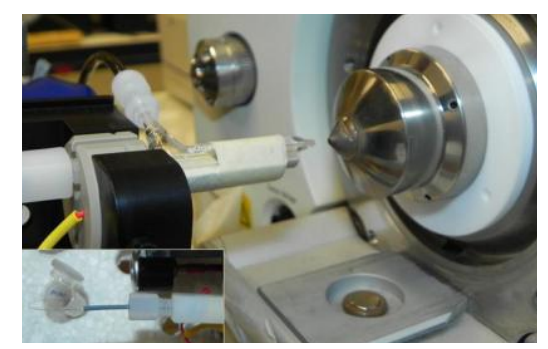

Figure 2. Detail from the SSI-MS system showing the nebulizer positioned in front of the mass spectrometer inlet.

ICP-MS: The concentration of calcium and copper in protein solutions was also determined using ICP-MS as a reference method to check the validity of LIBS measurements. For this, a quadrupole ICP-MS (NexION 300xx, PerkinElmer, Shelton, CT, USA) was used to measure isotopes ${ }^{43} \mathrm{Ca},{ }^{63} \mathrm{Cu}$ and ${ }^{65} \mathrm{Cu}$. Protein solutions containing these metals were introduced into the ICP-MS using a peristaltic pump and analyzed. Concentrations were determined using external calibration.

\section{Materials}

Calibration standards: Aqueous stock solutions were prepared by dissolving appropriate amounts of analytical grade chloride, nitrate or sulfate salts of metal ions $\left(\mathrm{CaCl}_{2}, \mathrm{Ba}\left(\mathrm{NO}_{3}\right)_{2}, \mathrm{CuSO}_{4}, \mathrm{FeCl}_{3}\right.$ purchased from Aldrich) in $18 \mathrm{M} \Omega \cdot \mathrm{cm}$ ultrapure water or a 1:1 mixture of ultrapure water-methanol, a more favorable solvent system for molecular mass spectrometry measurements. Standard solutions were prepared fresh by dilution with ultrapure water from the stock solutions.

Metalloprotein standards: Superoxide dismutase (SOD) was purchased from Aldrich (S7571-75KU). The protein consists of two identical subunits and is known to bind two copper(II) ions per molecule one on each subunit [30]. SOD standards were prepared by dilution of an appropriate amount of the protein in water or 1:1 water methanol mixture. $\alpha$-Lactalbumin (LALBA) was purchased from Aldrich (L5385$100 \mathrm{MG}$ ) and used without any further purification. The protein contains calcium (II) ions in 1:1 stoichiometry [31]. Solutions of the proteins for analysis were prepared by dissolving appropriate amounts of solid protein in a 1:1 mixture of ultrapure watermethanol. 


\section{Results and Discussion}

In order to ensure optimum sensitivity and reliability for the LIBS analysis of metal containing proteins, a series of experiments, investigating the influence of several critical parameters on the signal strength and spectra quality, were conducted. Considering the demands for reaching low LOD values for metal ion analysis, compatible with typical sample concentrations used in molecular mass spectrometry, maximum exploitation of the analyte mass in the aerosol droplets is of critical importance. This was achieved by employing laser pulses of relatively high energy, in the range of 190-200 $\mathrm{mJ}$, for plasma formation. Under these conditions, a strong continuum emission is produced immediately upon arrival of the laser pulse at the aerosol spray, which persists for approximately $10 \mu \mathrm{s}$, when atomic emission lines start growing (Fig. 3). It is noted that emissions from the metal analyte survive until ca 60-80 $\mu$ s after the laser pulse. The signal-to-background ratio (S/B) was found to be optimal for $\tau_{\mathrm{D}}>15 \mu \mathrm{s}$. Thus LIBS spectra were collected with a time delay, $\tau_{\mathrm{D}}=20$ $\mu \mathrm{s}$, and for a time gate, $\tau_{\mathrm{G}}=100 \mu \mathrm{s}$, in an effort to exclude contribution of the continuum at early times and exploit as much as possible the atomic emission signal in order to enhance the sensitivity of the analysis.

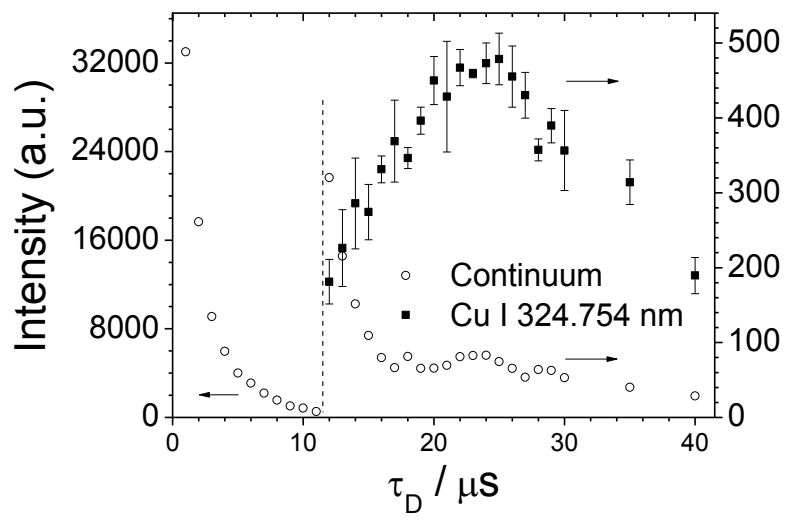

Figure 3. Time evolution of the LIBS signal originating from $\mathrm{Cu}$ I emission $(\lambda=$ $324.754 \mathrm{~nm}$ ) and from the continuum background collected at $323.2 \mathrm{~nm}$ (dashed line indicates change of scale for the continuum emission data from the left to the right intensity axis). Spectra were collected with $\tau_{\mathrm{G}}=500 \mathrm{~ns}$. Sample: aqueous solution, $\left.\left[\mathrm{Cu}^{2+}\right]=1.0 \times 10^{-4} \mathrm{M}\right)$.

Positioning the laser pulse focus with respect to the spray axis is also critical for achieving efficient sampling of the aerosol droplets and for maximizing the laserspray interaction. Examining the longitudinal position (d) of the laser pulse focus with respect to the nebulizer tip, it was found that signal intensity decreased with increasing $\mathrm{d}$, due to the reduction of droplet density arising from the conical geometry of the spray expansion (Fig. 4). A short value of d, approximately $2 \mathrm{~mm}$ from the tip, was selected for all measurements. Considering next the transverse arrangement, it is noted that because of the high pulse energy of the laser, plasma starts forming slightly in front of the actual focal point of the laser beam. Therefore, in order to ensure that the laser pulse interacted optimally with the aerosol and symmetrically with respect to 
its cone axis, the nebulizer was adjusted in a way that the laser focal point was located at $\mathrm{h}=2 \mathrm{~mm}$ past the spray axis. (See Fig. 1, lower)

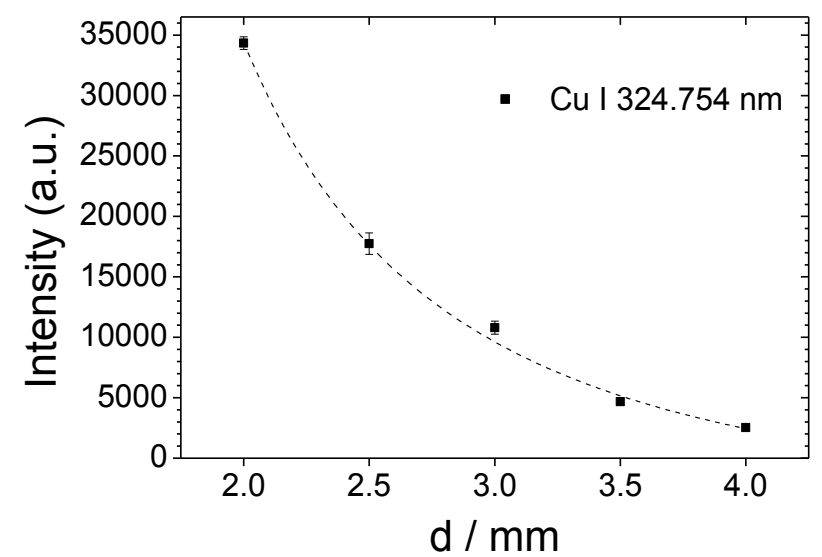

Figure 4. Emission intensity from $\mathrm{Cu} \mathrm{I}(\lambda=324.754 \mathrm{~nm})$ as a function of the distance, $\mathrm{d}$, between the tip of the nebulizer and the laser beam propagation axis (dashed line is a guide to the eye). Sample: aqueous solution, $\left[\mathrm{Cu}^{2+}\right]=2.0 \times 10^{-4} \mathrm{M}$.

Several test measurements were carried out under this geometry and single-shot LIBS spectra were collected with aqueous solutions of $\mathrm{CuSO}_{4}$. Each spectrum exhibited distinct emission lines of the metal analyte demonstrating that each and every laser pulse samples the spray. The relative standard deviation of such singleshot measurements was found to be on the order of $30-80 \%$, in sets of 200 spectra, with the higher variance observed in samples with concentration near the LOD. However the \%RSD of the emission intensity corresponding to the mean of 5 different measurements, representing averages of 200 spectra each, was less than $5 \%$. This was further verified by measuring a wide range of aqueous and/or methanolic (1:1 $\left.\mathrm{H}_{2} \mathrm{O}: \mathrm{CH}_{3} \mathrm{OH}\right)$ solutions of metal ion salts. As a result, the present experimental geometry and signal acquisition parameters were maintained throughout the experiments reported in this study.

Following this LIBS methodology, spectra were collected from solutions containing $\mathrm{Ca}, \mathrm{Ba}, \mathrm{Fe}$ and $\mathrm{Cu}$ ions at different concentrations (Fig. 5) and the appropriate emission lines were selected for analysis (Table 1). In all spectra, besides the sharp atomic lines, intense broad band emission features are evident arising from excited diatomic species such as $\mathrm{CN}\left(\mathrm{B}^{2} \Sigma^{+} \rightarrow \mathrm{X}^{2} \Sigma^{+}\right)$, $\mathrm{NH}\left(\mathrm{A}^{3} \Pi \rightarrow \mathrm{X}^{3} \Sigma^{-}\right)$or $\mathrm{OH}$ $\left(\mathrm{A}^{2} \Sigma^{+} \rightarrow \mathrm{X}^{2} \Pi\right)$ forming in the plasma plume [32],[33]. These bands can be a source of interference with the atomic line signals particularly at low levels of analyte concentration. Calibration curves (Fig. 5) obtained from these metal ion solutions exhibit excellent linearity $\left(\mathrm{R}^{2}>0.99\right)$. LOD values, determined on the basis of the $3 \sigma$ method [34], were found to be in the tens of $n g / m L$ range (Table 2) for $\mathrm{Ca}, \mathrm{Ba}$ and $\mathrm{Cu}$ and about an order of magnitude higher for Fe the latter mainly due to the low intensity of the Fe emission lines. These LOD values demonstrate the high analytical sensitivity of the current methodology. Finally, validation measurements led to determination of metal ion concentration in aqueous and/or methanolic solutions with accuracy (\% Recovery) greater than 95\%. In comparison with the present work, Almirall [35] and co-workers, working with a similar nebulizer, have reported LOD 
values of 0.6 and $0.7 \mu \mathrm{g} / \mathrm{mL}$ for $\mathrm{Ca}$ and $\mathrm{Ba}$, respectively, using a double-pulse LIBS approach (two laser pulses at $532 \mathrm{~nm}$ with $65 \mathrm{~mJ}$ of energy each, temporally separated by $50 \mathrm{~ns}$ with respect to one another). Also, Yalcin [36] and co-workers employed an ultrasonic nebulizer coupled with a membrane dryer that fed the droplets (diameter < $1.5 \mu \mathrm{m}$ ) into a small chamber where they were probed by single-pulse LIBS (laser pulse energy at $532 \mathrm{~nm}$, in the range of 20-150 mJ). LOD values for several elements were found to be in the $\mu \mathrm{g} / \mathrm{mL}$ range. Similarly, Groh et al [37] performing LIBS measurements on single droplets (diameter: 40-50 $\mu \mathrm{m}$ ) have achieved LOD values as low as $0.05 \mu \mathrm{g} / \mathrm{mL}$ for the case of $\mathrm{Ca}$ ions in $\mathrm{H}_{2} \mathrm{O}$.

Table 1. Emission lines used in the LIBS analysis of metal ions ${ }^{\mathrm{a}}$

\begin{tabular}{|c|c|c|c|}
\hline Element & Emission line (nm) & Transitions & Energy $\left(\mathrm{cm}^{-1}\right)$ \\
\hline $\mathrm{Cu} \mathrm{I}$ & 324.754 & $\begin{array}{c}3 d^{10} 4 p^{1} \rightarrow 3 d^{10} 4 s^{1} \\
{ }^{2} \mathrm{P}_{3 / 2} \rightarrow{ }^{2} S_{1 / 2}\end{array}$ & $30783.70-0.00$ \\
\hline $\mathrm{Fe} \mathrm{I}$ & 302.064 & $\begin{aligned} 3 d^{7} 4 p^{1} & \rightarrow 3 d^{6} 4 s^{2} \\
\left(y^{5} D_{4}\right) & \rightarrow\left(a^{5} D_{4}\right)\end{aligned}$ & $33095.94-0.00$ \\
\hline $\mathrm{Ca} \mathrm{I}$ & 422.673 & $\begin{array}{c}(3 p)^{6}(4 s)^{1}(4 p)^{1} \rightarrow(3 p)^{6}(4 s)^{2} \\
\left({ }^{1} P_{1}\right) \rightarrow\left({ }^{1} S_{0}\right)\end{array}$ & $23652.30-0.00$ \\
\hline $\mathrm{Ba}$ II & 455.403 & $\begin{aligned}(5 p)^{6}(6 p)^{1} & \rightarrow(5 p)^{6}(6 s)^{1} \\
\left({ }^{2} P_{3 / 2}\right) & \rightarrow\left({ }^{2} S_{1 / 2}\right)\end{aligned}$ & $21952.40-0.00$ \\
\hline
\end{tabular}

a Data from NIST Atomic Spectra Database [38] 

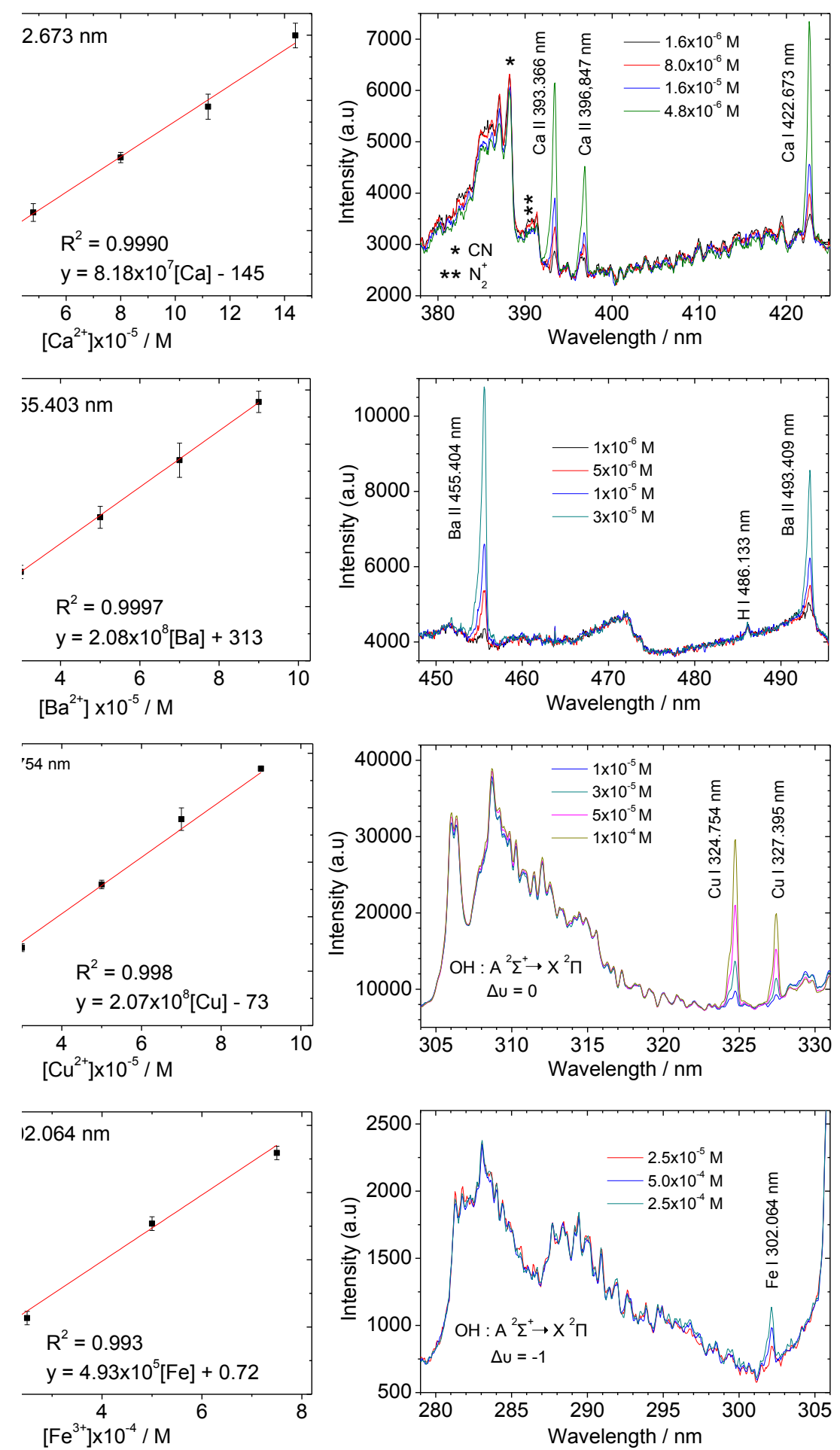

Figure 5. Calibration curves and indicative LIBS spectra for a) $\mathrm{Ca}^{2+}$ in $\mathrm{H}_{2} \mathrm{O}$ ), b) $\mathrm{Ba}^{2+}$ in $\mathrm{H}_{2} \mathrm{O}$ ), c) $\mathrm{Cu}^{2+}$ in $1: 1 \mathrm{CH}_{3} \mathrm{OH}-\mathrm{H}_{2} \mathrm{O}$, and d) $\mathrm{Fe}^{3+}$ in $1: 1 \mathrm{CH}_{3} \mathrm{OH}-\mathrm{H}_{2} \mathrm{O}$. 
Table 2. LOD values and results of validation study for metal ions analyzed by LIBS.

\begin{tabular}{|c|c|c|c|c|c|c|c|c|}
\hline \multirow{2}{*}{$\begin{array}{c}\text { Eleme } \\
\text { nt }\end{array}$} & \multirow{2}{*}{$\begin{array}{l}\text { Emission } \\
\text { line (nm) }\end{array}$} & \multicolumn{4}{|c|}{ LOD $(\mu \mathrm{g} / \mathrm{mL})$} & \multicolumn{2}{|c|}{$\begin{array}{c}\text { Test sample } \\
\text { concentration }\end{array}$} & \multirow{2}{*}{$\begin{array}{c}\% \\
\text { Recovery }^{\mathrm{d}}\end{array}$} \\
\hline & & $\begin{array}{l}\text { Curren } \\
\text { t work }\end{array}$ & $\begin{array}{c}{[35} \\
]\end{array}$ & $\begin{array}{c}{[36} \\
] \\
\end{array}$ & $\begin{array}{c}{[37} \\
]\end{array}$ & $(\mathrm{M})$ & $\begin{array}{c}\mu \mathrm{g} / \mathrm{mL} \\
)\end{array}$ & \\
\hline $\mathrm{Cu} \mathrm{I}$ & 324.754 & 0.033 & --- & $\begin{array}{c}1.9 \\
9\end{array}$ & --- & $4 \times 10^{-5}$ & 2.5 & 100.3 \\
\hline $\mathrm{Fe} \mathrm{I}$ & 302.064 & 0.65 & --- & --- & --- & $5 \times 10^{-5}$ & 2.8 & 95.6 \\
\hline $\mathrm{Ca} \mathrm{I}$ & 422.673 & 0.015 & $\underset{b}{0.6}$ & $\begin{array}{l}1.8 \\
3^{\mathrm{a}}\end{array}$ & $\begin{array}{c}0.0 \\
5^{\mathrm{a}}\end{array}$ & $1 \times 10^{-5}$ & 0.4 & 101.2 \\
\hline $\mathrm{Ba}$ II & 455.403 & 0.027 & $\underset{c}{0.7}$ & --- & --- & $7 \times 10^{-6}$ & 0.1 & 100.7 \\
\hline
\end{tabular}

${ }^{\text {a }}$ value determined on the basis of the $393.366 \mathrm{Ca}$ II emission line

${ }^{b}$ value determined on the basis of the $396.847 \mathrm{Ca}$ II emission line

c value determined on the basis of the 493.409 Ba II emission line

d \% Recovery $=[$ Recovered (Measured) Concentration $/$ True Concentration $] \times 100 \%$

\section{Metalloprotein analysis}

Two metal containing biomolecules, superoxide dismutase (SOD) and $\alpha$ lactalbumin (LALBA), were studied using both LIBS and SSI-MS to demonstrate the complementarity of the information obtained by the two methods. In addition, it was our objective to show that both detection systems could be operated efficiently using an identical microflow pneumatic nebulizer for sample introduction. Solution concentrations were the same for both analyses.

LIBS measurements were performed in solutions of SOD $(1.66 \mathrm{mg} / \mathrm{mL})$ and LALBA $(0.62 \mathrm{mg} / \mathrm{mL})$ in ultrapure $\mathrm{H}_{2} \mathrm{O}-\mathrm{CH}_{3} \mathrm{OH}$ matrix $(50 \% \mathrm{v} / \mathrm{v})$, a solvent system commonly used in mass spectrometric studies. The concentration of the analyzed protein is in the range of a few $\mathrm{mg} / \mathrm{mL}$, which is a typical concentration used in mass spectrometry experiments. Prior to MS analysis, solutions were acidified by addition of acetic acid at $5 \% \mathrm{v} / \mathrm{v}$.

The SSI mass spectrum of SOD obtained in water (Fig. 6A) shows a series of peaks in the $\mathrm{m} / \mathrm{z}$ range of $1000-2000$ corresponding to the protein in different charge states. Deconvolution of these spectra revealed the molecular mass of SOD to be 15598.2 Da. This in fact represents the molar mass of one of the two identical subunits of the protein, which is known to dissociate into its subunits in an acidic environment. The concentration of $\mathrm{Cu}^{2+}$ ions in the analyzed SOD solution was measured by LIBS and was found to be $4.91 \times 10^{-5} \mathrm{M}$, which was also confirmed by ICP-MS analysis. On the basis of the molecular mass measured and the mass to volume concentration of the SOD solution, the molar concentration of the SOD (dimer) solution is calculated to be $5.3 \times 10^{-5} \mathrm{M}$. Taking into account that each SOD subunit can bind one $\mathrm{Cu}^{2+}$ ion [30], the bound $\mathrm{Cu}$ concentration of the protein solution, provided that each SOD dimer contains $2 \mathrm{Cu}$ atoms, would be expected to be $10.6 \times 10^{-5} \mathrm{M}$. This turns out to be approximately a factor of 2 higher compared to what was actually measured by LIBS and ICP-MS. This discrepancy may be due to a number of factors such as protein purity or loss of metal during protein isolation and 
purification. Unfortunately, the supplier does not provide any information regarding metal - protein stoichiometry for their product. Therefore the data obtained from the complimentary use of LIBS and SSI-MS reveals the molecular mass of the protein, and that not all available protein sites are occupied by $\mathrm{Cu}$ ions.

Similarly MS analysis of LALBA resulted in a molecular mass of 14,180 Da. Based on this value the molar concentration of LALBA, in the solution analyzed, was calculated to be $4.37 \times 10^{-5} \mathrm{M}$ and, given that the metal to protein stoichiometry is $1: 1$ [31], the concentration of $\mathrm{Ca}$ ions in the solution is expected to be the same. Analysis by LIBS determined the concentration of $\mathrm{Ca}$ ions to be $8.17 \times 10^{-5} \mathrm{M}$, which was also confirmed by ICP-MS analysis. The deviation may be attributed to the use of excess of $\mathrm{Ca}^{2+}$ during the preparation of this reagent in order to ensure ion saturation of the protein. In the product specification sheet it is stated that the molar ratio of $\mathrm{Ca}^{2+} /$ LALBA is $\geq 1$.
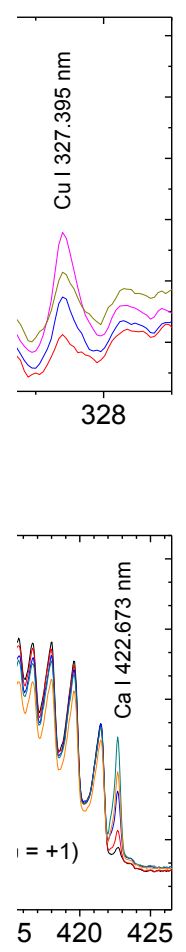

Figure 6. Mass and LIBS spectra obtained in the analysis of a) SOD and b) LALBA solutions. In the MS analysis the solvent matrix was $5 \%$ acetic acid/water while in LIBS analysis a $\mathrm{H}_{2} \mathrm{O}-\mathrm{CH}_{3} \mathrm{OH}$ matrix was used.

\section{Conclusions}

We have demonstrated, for the first time, the use of sonic spray ionization mass spectrometry (SSI-MS) in combination with laser induced breakdown spectroscopy (LIBS) for the analysis of metalloprotein solutions. Considering the LIBS technique, 
it is evident that highly sensitive detection of several metal ions can be achieved probing the aerosol produced by a pneumatic nebulizer and this holds also for the analysis of the metalloprotein solutions. SSI-MS on the other hand permits the measurement of the molar mass of the metal-containing biomolecules under native conditions. The information about the elemental composition of the metalloproteins provided by LIBS is complementary to molar mass data obtained with SSI-MS. It permits for the improved characterization of large biomolecules using a low resolution MS or even large MDa protein complexes when using high resolution MS.

A number of technical aspects are to be further investigated, such as for example the use of a high repetition rate laser for probing the aerosol that would increase data collection rate and consequently reduce analysis time, permitting the efficient use of LIBS as a liquid chromatography detector. Such an improvement would enable high throughput analysis both at the molecular and atomic level and could open up prospects for efficient screening of metal-containing biomolecules in mixtures. Additional research is needed in order to investigate the applicability of the proposed methodology for the characterization of different types of metal-organic complexes and a broader spectrum of metal-containing biomolecules. The next step is to implement the simultaneous use of SSI-MS and LIBS, namely to employ a single pneumatic nebulization system as a sample source and carry out LIBS analysis just in the space between the nebulizer tip and the mass spectrometer inlet.

\section{Acknowledgements}

This research was supported in part by a graduate fellowship (Contract: 2013 - Е ППА - ПE3 - 2571) to KM by the Hellenic Scholarships Foundation (IKY) in the framework of the "IKY Fellowships" project through the Operational Program "Education and Lifelong Learning" of the European Social Fund (ESF) of the

National Strategic Reference Framework (NSRF, 2007-2013). Experiments were performed at the Ultraviolet Laser Facility operating at IESL-FORTH with support from the Laserlab-Europe project funded through the H-2020 Research and Innovation Programme of the EC (grant agreement no 654148). The authors also wish to acknowledge co-funding of this research by the European Union-European Regional Development Fund and the Greek Ministry of Education / EY $\Delta$ E-ETAK 
through program NSRF 2007-2013 / EПAN II / Action "SYNERGASIA" (095YN13-832). 


\section{References}

[1] K.A. Francesconi, J.S. Edmonds, A novel arsenical in clam kidney identified by liquid chromatography/electrospray ionisation mass spectrometry., Rapid Commun. Mass Spectrom. 15 (2001) 1641-6. doi:10.1002/rcm.420.

[2] P. Jitaru, G. Cozzi, A. Gambaro, P. Cescon, C. Barbante, Simultaneous speciation analysis of glutathione peroxidase, selenoprotein $\mathrm{P}$ and selenoalbumin in human serum by tandem anion exchange-affinity HPLC and on-line isotope dilution ICP-quadrupole MS, (2008) 661-669. doi:10.1007/s00216-008-2043-7.

[3] S.S. Kannamkumarath, K. Wróbel, K. Wróbel, J.A. Caruso, Speciation of Arsenic in Different Types of Nuts by Ion Chromatography-Inductively Coupled Plasma Mass Spectrometry, J. Agric. Food Chem. 52 (2004) 14581463. doi:10.1021/jf0351801.

[4] S. McSheehy, M. Marcinek, H. Chassaigne, J. Szpunar, Identification of dimethylarsinoyl-riboside derivatives in seaweed by pneumatically assisted electrospray tandem mass spectrometry, Anal. Chim. Acta. 410 (2000) 71-84. doi:10.1016/S0003-2670(00)00706-6.

[5] W. Maher, F. Krikowa, M. Ellwood, S. Foster, R. Jagtap, G. Raber, Overview of hyphenated techniques using an ICP-MS detector with an emphasis on extraction techniques for measurement of metalloids by HPLC - ICPMS, Microchem. J. 105 (2012) 15-31. doi:10.1016/j.microc.2012.03.017.

[6] A. Raab, A.A. Meharg, The Nature of Arsenic-Phytochelatin Complexes in Holcus lanatus and Pteris cretica 1, 134 (2004) 1113-1122. doi:10.1104/pp.103.033506.

[7] E. Schmeisser, W. Goessler, N. Kienzl, K.A. Francesconi, Direct measurement of lipid-soluble arsenic species in biological samples with HPLC-ICPMS, (2005) 948-955. doi:10.1039/b502445e.

[8] J. Feldmann, P. Salaün, E. Lombi, Critical review perspective: elemental speciation analysis methods in environmental chemistry - moving towards methodological integration, (2009) 275-289. doi:10.1071/EN09018.

[9] H.R. Hansen, S.A. Pergantis, Identification of Sb (V) complexes in biological and food matrixes and their stibine formation efficiency during hydride generation with ICPMS detection, Anal. Chem. 79 (2007) 5304-5311. doi:10.1021/ac070130r.

[10] Y. Lu, A. Rumpler, K.A. Francesconi, S.A. Pergantis, Quantitative selenium speciation in human urine by using liquid chromatography-electrospray tandem mass spectrometry., Anal. Chim. Acta. 731 (2012) 49-59. doi:10.1016/j.aca.2012.04.016.

[11] V. Nischwitz, S.A. Pergantis, First report on the detection and quantification of arsenobetaine in extracts of marine algae using HPLC-ES-MS/MS, Analyst. 130 (2005) 1348-1350. doi:10.1039/b509547f.

[12] V. Nischwitz, S.A. Pergantis, Mapping of arsenic species and identification of a novel arsenosugar in giant clams Tridacna maxima and Tridacna derasa using advanced mass spectrometric techniques, Environ. Chem. 4 (2007) 187-196. doi:10.1071/EN07009. 
[13] H. Rusz Hansen, S.A. Pergantis, Detection of antimony species in citrus juices and drinking water stored in PET containers, J. Anal. At. Spectrom. 21 (2006) 731. doi:10.1039/b606367e.

[14] V.G. Santos, T. Regiani, F.F.G. Dias, W. Romão, J.L.P. Jara, C.F. Klitzke, et al., Venturi easy ambient sonic-spray ionization, Anal. Chem. 83 (2011) 13751380. doi:10.1021/ac102765z.

[15] A.M. Porcari, G.D. Fernandes, D. Barrera-Arellano, M.N. Eberlin, R.M. Alberici, Food quality and authenticity screening via easy ambient sonic-spray ionization mass spectrometry, Analyst. 141 (2016) 1172-1184. doi:10.1039/C5AN01415H.

[16] D.A. Cremers, L.J. Radziemski, Handbook of Laser-Induced Breakdown Spectroscopy, John Wiley \& Sons, Ltd, Chichester, UK, 2006. doi:10.1002/0470093013.

[17] G. Galbács, A critical review of recent progress in analytical laser-induced breakdown spectroscopy, Anal. Bioanal. Chem. 407 (2015) 7537-7562. doi:10.1007/s00216-015-8855-3.

[18] R. Gaudiuso, M. Dell'Aglio, O. de Pascale, G.S. Senesi, A. de Giacomo, Laser induced breakdown spectroscopy for elemental analysis in environmental, cultural heritage and space applications: A review of methods and results, Sensors. 10 (2010) 7434-7468. doi:10.3390/s100807434.

[19] J. Rakovský, P. Čermák, O. Musset, P. Veis, A review of the development of portable laser induced breakdown spectroscopy and its applications, Spectrochim. Acta - Part B At. Spectrosc. 101 (2014) 269-287. doi:10.1016/j.sab.2014.09.015.

[20] M. Kotzagianni, E. Kakkava, S. Couris, Laser-induced breakdown spectroscopy (LIBS) for the measurement of spatial structures and fuel distribution in flames, Appl. Spectrosc. 70 (2016) 627-634. doi:10.1177/0003702816631296.

[21] X. Yu, Y. Li, X. Gu, J. Bao, H. Yang, L. Sun, Laser-induced breakdown spectroscopy application in environmental monitoring of water quality: a review, Environ. Monit. Assess. 186 (2014) 8969-8980. doi:10.1007/s10661014-4058-1.

[22] L.J. Radziemski, T.R. Loree, D.A. Cremers, N.M. Hoffman, Time-Resolved Laser- Induced Breakdown Spectrometry of Aerosols, Anal. Chem. 55 (1983) 1246-1252. doi:0003-2700/83/0355-1246\$01.50/0.

[23] M.H. Nunez, P. Cavalli, G. Petrucci, N. Omenetto, Analysis of Sulfuric Acid Aerosols by Laser-Induced Breakdown Spectroscopy and Laser-Induced Photofragmentation, 54 (2000) 1805-1816.

[24] J.E.E. Carranza, B.T.T. Fisher, G.D.D. Yoder, D.W.W. Hahn, On-line analysis of ambient air aerosols using laser-induced breakdown spectroscopy, Spectrochim. Acta - Part B At. Spectrosc. 56 (2001) 851-864. doi:10.1016/S0584-8547(01)00183-5.

[25] P.K. Diwakar, S. Groh, K. Niemax, D.W. Hahn, Study of analyte dissociation and diffusion in laser-induced plasmas: implications for laser-induced breakdown spectroscopy, J. Anal. At. Spectrom. 25 (2010) 1921. doi:10.1039/c0ja00063a. 
[26] B.T. Fisher, H.A. Johnsen, S.G. Buckley, D.W. Hahn, Temporal Gating for the Optimization of Laser-Induced Breakdown Spectroscopy Detection and Analysis of Toxic Metals, 55 (2001).

[27] J.L. Todolí, J.M. Mermet, Sample introduction systems for the analysis of liquid microsamples by ICP-AES and ICP-MS, Spectrochim. Acta - Part B At. Spectrosc. 61 (2006) 239-283. doi:10.1016/j.sab.2005.12.010.

[28] M.M. Antonakis, A. Tsirigotaki, K. Kanaki, C.J. Milios, S.A. Pergantis, Bipolar mass spectrometry of labile coordination complexes, redox active inorganic compounds, and proteins using a glass nebulizer for sonic-spray ionization, J. Am. Soc. Mass Spectrom. 24 (2013) 1250-1259. doi:10.1007/s13361-013-0668-z.

[29] K. Kanaki, S.A. Pergantis, Use of 3-nitrobenzonitrile as an additive for improved sensitivity in sonic-spray ionization mass spectrometry, Rapid Commun. Mass Spectrom. 28 (2014) 2661-2669. doi:10.1002/rcm.7064.

[30] M. Borges-Alvarez, F. Benavente, M. Vilaseca, J. Barbosa, V. Sanz-Nebot, Characterization of superoxide dismutase 1 (SOD-1) by electrospray ionization-ion mobility mass spectrometry, J. Mass Spectrom. 48 (2013) 6067. doi:10.1002/jms.3128.

[31] N.M. Hiraoka, Y., T. Segawa, K. Kuwajima, S. Sugai, alpha-Lactalbumin: A Calcium Metalloprotein, Biochem. Biophys. Res. Commun. 95 (1980) 10981104.

[32] M. Adamson, A. Padmanabhan, G.J. Godfrey, S.J. Rehse, Laser-induced breakdown spectroscopy at a water/gas interface: A study of bath gasdependent molecular species, Spectrochim. Acta - Part B At. Spectrosc. 62 (2007) 1348-1360. doi:10.1016/j.sab.2007.10.022.

[33] R. Glaus, J. Riedel, I. Gornushkin, Insight into the Formation of Molecular Species in Laser-Induced Plasma of Isotopically Labeled Organic Samples, Anal. Chem. 87 (2015) 10131-10137. doi:10.1021/acs.analchem.5b02926.

[34] J.N. Miller, J.C. Miller, Statistics and Chemometrics for Analytical Chemistry, 6th ed., Pearson Education Canada, 2010.

[35] E.M. Cahoon, J.R. Almirall, Quantitative Analysis of Liquids from Aerosols and Microdrops Using Laser Induced Breakdown Spectroscopy, Anal. Chem. 84 (2012) 2239-2244. doi:10.1021/ac202834j.

[36] N. Aras, S.Ü. Yeşiller, D.A. Ateş, Ş. Yalçın, Ultrasonic nebulization-sample introduction system for quantitative analysis of liquid samples by laser-induced breakdown spectroscopy, Spectrochim. Acta Part B At. Spectrosc. 74-75 (2012) 87-94. doi:10.1016/j.sab.2012.06.017.

[37] S. Groh, P.K. Diwakar, C.C. Garcia, A. Murtazin, D.W. Hahn, K. Niemax, $100 \%$ Efficient sub-nanoliter sample introduction in laser-induced breakdown spectroscopy and inductively coupled plasma spectrometry: Implications for ultralow sample volumes, Anal. Chem. 82 (2010) 2568-2573. doi:10.1021/ac901966z.

[38] Atomic Spectra Database, National Institute of Standards and Technology, http://www.nist.gov/pml/data/asd.cfm. 


\section{MANUSCRIPT NO-EMSLIBS2015-11}

\section{HIGHLIGHTS}

Sonic-spray ionization (SSI) mass spectrometry (MS) and laser induced breakdown spectroscopy (LIBS) were used in the analysis of metal-containing biomolecules.

LIBS measurements were performed for the first time on aerosols of biomolecule containing solutions provided reliable determination of the biomolecule metal ion content.

The results strongly suggest that LIBS can be integrated with SSI-MS leading to a fast method for obtaining simultaneously atomic and molecular data from biomolecules. 